\title{
Reconsidering Autistic Narrative Agency and the Autobiography: The Curious Case of Tito Mukhopadhyay's Beyond the Silence: My Life, the world and Autism
}

\author{
Shibashish Purkayastha \\ PhD Research Scholar (English), Department of Humanities and Social Sciences, Indian \\ Institute of Technology, Guwahati, Assam, India. \\ Email: shibashish.purkayastha@gmail.com
}

\begin{abstract}
The primary purpose of this paper will be to investigate whether in narrativizing the subtleties of shame and stigma into the form of a coherent autobiography, the autistic autobiographer, Tito Mukhopadhyay, intentionally or unwittingly, explores different avenues regarding the types of autobiographical accounts, which causes us to re-imagine our understandings of autism and numerous other forms of cognitive impairment, and move past excessively deterministic and essentialist/normalizing biomedical discourses of cure and care. The study shall work within theories of postcolonialism, phenomenology, narrative theory, trauma studies and life writing studies. A literature review based on the extant scholarship in the field of life writing studies, health humanities and other disciplines has been conducted and after the identification of the research gap, this study chiefly seeks to purport that the lived experience of autism can be at variance with the prevalent biomedical and neurological understanding of this condition. By taking into cognizance the various material realities of the patients as evinced in their autie-biographies, I maintain that this information can come to the aid of medical practitioners, psychologists and psychoanalysts in considering the subjective dimensions of experience of autism apart from the monolithic and monolingual truth as evidenced by a scientific enquiry of autism spectrum disorder. This also suggests some appropriate conversation starters about the crossing points between a debilitating condition and the act of composing one's life narrative with such a debilitating condition.
\end{abstract}

Keywords: autobiography, trauma, agency, narrative, autism, stigma

\section{INTRODUCTION}

My motivation in this paper will be twofold: firstly, I plan to show how Tito Mukhopadhyay in his autobiography fittingly titled Beyond the Silence: My Life, the world and Autism (200o), investigates the tropes of shame and disgrace that have been vital to his encounters of living with a psychologically handicapping condition. In his story, two things appear to surface up: the quest for a specific 'narrative mode' that would sufficiently depict the materiality of his crippling condition and the need to investigate the relations between the brain/mind dichotomy, the body and the exercise of creativity. Taking Thomas Couser's signal, I seek to endeavour that Mukhopadhyay's story, while giving an insider's point of view on a form of cognitive impairment, likewise seeks to give a lie to suppositions encompassing the clinical information on the

(C) AesthetixMS 2020. This Open Access article is published under a Creative Commons Attribution Non-Commercial 4.o International License (http://creativecommons.org/licenses/by-nc/4.o/), which permits non-commercial re-use, distribution, and reproduction in any medium, provided the original work is properly cited. For citation use the DOI. For commercial re-use, please contact editor@rupkatha.com. 
condition. Over the span of my paper, drawing for the most part from critical disability studies, narrative theory, poststructuralism, phenomenology and psychoanalysis, I contend that, stories of this sort, which foreground the material realities of and the disgrace accruing from such an incapacitating condition, appear to have a distinct 'effectual' and 'visceral' quality to them, which can't be effectively subsumed inside a specific literary structure. This additionally brings to the front line the pliability or malleability of life accounts as a genre itself. These sort of 'autiebiographies' endeavor to challenge life narrative's alleged dependence on a stable sense of self to project trustworthiness in foregrounding the narrator's fragmentariness, depersonalization, incompleteness and logical inconsistency in narration. Furthermore, I maintain that, Mukhopadhyay's brief memory, his evidently disconnected and elliptical portrayals envision us to re-imagine the type of autobiographical narrative as a genre itself. The expanded enthusiasm for the issues of incapacity and debility has prompted an expansion of personal histories, journals and books which depict the materiality of living with a [physically] crippling condition. Literary scholars, film theorists and social scientists have, for the most part, focused on parts of physical incapacity while certain inabilities accruing from psychological hindrances went unattended. Curiously, however, there has been a noteworthy advancement in the field of literary criticism in investigating issues of cognitive disabilities. By the same token, Stuart Murray avers that the frequently concealed nature of intellectual debilitation is, potentially, something that even researchers working in the field of disability and cultural studies, or those working in neuroscientific research, have failed to surmise (25). This narrative enthusiasm in the field of disability studies by and large and of autism narratives, in particular, is because of the advancements in the field of neurosciences.

Disability/Debility/Illness Life writing have effectively acted as counter talks to predominant clinical and social understandings of debility and illness. They tend to challenge and undermine a host of abusive belief systems and destabilize any case to a regularizing or fixed focus. Also, as opposed to omitting the body, these accounts demand that critical scrutiny's, observation, and subjectivity are totally grounded in the "poetics and politics" of the lived [suffering] body. What we find in disability life writing is a cognizant rendering of altered physicality in prose (Couser 150). In that capacity, disability life writing offers an important "return to the visceral in disability studies", bringing about theorizations that are at once personal, social and political. These writers had likewise set their scrutiny against the use of terms, for example, deficiency, deficit and debilitation while depicting the condition. Experience of living with, and access to the states of regular daily existence are integrated up in all circumstances. Tito Mukhopadhyay, in one of his interviews, expressed that, coming out as disabled, without what a culture assumes as incapacity's typical nearness, appears to be a marginally different issue. If the autistic person, for instance, is to come out, she or he should effectively deny her/his own position in, as Irving Zola has put it, the universe of the normal. It is the very perceivability of normalcy that must be hushed, overlooked, denied. It is the individual's expected and evident position in the standard that makes coming out as, and going into, incapacity an alternate issue for individuals whose distinctions don't promptly appear to other people who unquestioningly accept, and in this way "see" just, the structures of commonality (npag).Heidi Lourens in her article "Driving in unheard silence: Disability and the politics of shutting up" had recommended that, the politics of silence is pivotal to the experience of living with inability. She expresses that, disability related silences are generally made through the conversion of distant physical and social situations and the mental disguise of these universes (npag). The disgrace, shame, stigma and vilification faced by people with autism often aggravate their health conditions. In various manners and to various degrees, individuals in numerous nations see autism disorders as synonymous to disillusionment, 
irritation, disgrace or lack. As indicated by certain analysts, disgrace may shield the person from looking for communities, from taking an interest completely in their networks. Basically, such forms of cognitive disability impact personal conduct standards of a person with the condition. The expression "autism" was coined by Swiss psychiatrist Eugene Bleuler in 1908. The name originates from the Greek word "autos" (alone) and alludes to the psychopathological propensity of getting some distance from the outside world and concentrating on the inward world. At first, autism and autistics were 'treated' alongside schizophrenics. However, the term entered into the medical classification when Austrian-American psychiatrist and physician Leo Kanner first described autism in his article "Autistic Disturbances of Affective Contact" which appeared in Nervous Child in 1943 where he captured the three core features of what later came to be called Autism Spectrum Disorders (ASDs): disturbances of social relationships, limited use of language to communicate, and fixed repetitive interests and routines (Kanner, 1943).

My perusing of Mukhopadhyay's autobiography is a move away from the deterministic perspective on incapacity and I suggest that, Mukhopadhyay's account imagines better approaches for contemplating bodies and self-portraying accounts of autism and similar cognitive debilities. In Mukhopadhyay's autobiographical narrative, he seeks to bring to the foreground that people with autism spectrum disorders are not equipped for responding sentiments similarly as an individual (neurotypical) without the condition. He further notices that, autism does frequently influence a person's capacity to comprehend implicit relational correspondence, so somebody with autism probably may not necessarily identify pity dependent on one's body language or mockery in one's manner of speaking.

Tito Rajarshi Mukhopadhyay was diagnosed with 'autism' when he was three. He was raised in Bangalore and Mysore and moved to the U.S with his mother, at thirteen. By that point, Tito Mukhopadhyay had become a sensation in the medically introverted network who was set on resisting and upsetting regular biomedical understandings of the condition. Beyond the Silence: My Life, the world and Autism was published when he was twelve. In Mukhopadhyay's account, the thought of disabling silence is connected with the absence of or with lacking verbal abilities resulting in the lack of much relational correspondence with the environment. Apparently, language does not solely serve the autistics as a method for correspondence, in this manner in their examination of the role of silence in reference to verbal correspondence is out of inquiry. As Anna Bieniarz in her paper "Loneliness and Silence in Autism - Implications for Psychotherapy" notes that silence(s) in autism may show up in various degrees. The most elevated level of silence is showed in mutism and is deciphered as complete silence, making a hindrance isolating autistics from the equipped discourse users. The silence encompassing autistics has the best therapeutic value; it diminishes the quantity of stimuli from the external environment. In these cases, silence fills in as a resistance system, shielding the unformed intra-mystic space from the confusion, and chaos testing with the breaking down of the character (2011: web).

\section{LITERATURE REVIEW}

Ian Hacking in his article "Autistic Autobiography" offering a phenomenological investigation of autistic writings from an insider's point of view, opines that there is no pre-existing language to comprehend autism dependent on popular discourses by alluding to Wolfgang Kohler and Wittgenstein and further keeps up that one can comprehend the autist straightforwardly without an a priori comprehension of the condition. By citing instances of Temple Grandin and Tito Mukhopadhyay, Hacking offers that their life-narratives are not mere matter-of-fact observations 
but a learning [visceral and sensory] process which do not really follow the methods by which [neurodiverse] people come to acquire speech (2009: web). Likewise, the focal proposition of Uta Frith and Francesca Happe in their paper on "Theory of Mind and Self-Consciousness: What is it Like to be Autistic?" state that understandable autists appear to appear to show an express hypothesis of the brain by a moderate and cautious learning process, comparably as they appear to show a hesitance to a long and tangled course of learning (1999: 2).

Mark Osteen in his book Autism and Representation calls attention to the "blindsightedness" of the field of Disability Studies with respect to certain intellectual disabilities. The field has generally neglected to investigate different psychological and formative incapacities. He further states "Are academics- even disabled academics- unaware of our cognitive privilege? Is disability studies guilty of cognitive ableism- a prejudice against those who cannot compose articles and books, compete for advocacy space and contribute to disability scholarship?" (2008: 5). Osteen tries to fill this lacuna by bringing in the conversations relating to intellectual and developmental disabilities. Alice Wexler in her book Autism in a Decentering World expresses the curious nonappearance of first-person narrative accounts of individuals living with autism. She proceeds to express that with the assistance of assistive innovations and facilitated correspondence, there have been an expansion in the number of visual accounts since the 1970s. Her central thesis in the book is to propose an alternative epistemology of autism which does not consider the materiality of autism spectrum disorders. She alludes to the Enlightenment which made an exacting hierarchy between the mind/body and certain other hierarchical knowledge systems which created the distinction between normality/abnormality. In the course of propelling her contention, Wexler refers to the various contentions which have been progressed by philosophers, scientists and neuropsychologists. They indicated the evidently discontinuous, fragmented, pluralist and relational self not merely restrictive to specific areas of the brain with no self-aware center but also personal experience of the person living with autism, and the scientists themselves (2016: 100-102). Ralph James Savarese in his essay "Toward a Postcolonial Neurology: Autism, Tito Mukhopadhyay and a new Geo-poetics of the Body" underscores that specific case accounts, for example, that of Oliver Sacks et. al. portrays the variations of human diversity yet are less intrigued into investigating the subtleties of the neurological condition. By utilizing a term "postcolonial neurology" he implies the heterogeneity and the materiality of cerebral difference. By falling back on George Lakoffs thought in his book "The Philosophy of the Flesh", Savarese proposes a comparative term "autistic memoir in the flesh" in which he proceeds to offer a nuanced comprehension of autistic embodiment. He composes that upon the success of Tito's autobiography, he was welcomed over by Portia Iverson-fellow benefactor of CAN (Canucks Autism Network-which was later coordinated with Autism Speaks in 2006), to hold him as an example to the pupils at the CAN and assist them with obtaining relational abilities. A significant aspect of postcolonial neurology, to Savarese, is Tito's understanding of radical synesthesia. What hangs out, however, in Tito's autobiographical narrative is imagining a sort of "aroundness" attending to its postcoloniality by challenging the hierarchies of biomedical research and hegemony of neurotypicality. (2010: web).

Uta Frith in "The Changing Faces of Autism" traces a trajectory of the changes in public perception of autism, but however maintains that, despite everything, it has a long way to go. Initially it was exclusively seen as a learning disability and mental retardation. Alluding to Hans Asperger's contention that autism has numerous aspects, and concludes her exposition by expressing that there ought to be more exchanges and discussions about the distinctions in the brain and mental make-up (2008: 37). Leni Van Goidsenhoven in her article “'Autie-Biographies:' Life Writing Genres and Strategies from an Autistic Perspective” recommends the possibility of 
approaching the idea of autism and autobiography in what she calls "autie-biography" and approaches the divergent corpus of autism narratives utilizing three frameworks in particular genre study, pragmatic genre perspective and socio-rhetorical genre perspective in analysing two disparate autism narratives that of Donna Williams and Schipper Landschip, and opines that autism narratives are performative in that they have moulded the significance of being autistic. She states that the methodologies she utilizes are just variations within the larger corpora of autism narratives. This heterogeneity of autism narratives which utilize the performativity of an assortment of genres shape autistic identity (2017: 9).

Alyssa Hillary in her article "Autist/Biography" expresses that it is the need of the day to go past commonsensical understandings of autism and necessitates approaching autism as a theory of the mind. Autist individuals write themselves to existence, as indicated by Hillary. One need not trace or follow a pattern in these narratives for similar symptoms, for they celebrate fluidity of their existence with autism and not symptom specific as per a neurotypical standard (2020: 330-335). Julia Kellman in her article on "Drawing with Peter: Autobiography, Narrative and the Art of a Child with Autism" analyses the artworks of young precocious eight-year old child with autism and appears to stress on the situatedness of autism narratives and the narrative potential of such stories (2015: 258-273).

Irene Rose, along comparative lines, offering a review of autistic autobiography in her paper "Autistic autobiography or autistic life narrative" focuses on their attitudinal variations. She insists on the relational quality of these narratives which make them potent 'testimonios'. Autistic autobiographies have the ability to convert certain sovereign certainties of conventional autobiographical narratives into subversive tales of autistic authority (2008:10). In my paper, I extend Rose's contention further to make a case that Tito's apparent precocious state and his capacity at comprehending things with the aid of recognizable scenes and objects makes him the architect of his own narrative, albeit the narration rests on his mother and grandmother. Alicia Broderick and Ari Ne'eman in "Autism as Metaphor: narrative and counter-narrative" focuses on the disruptive nature of the metaphors and symbols in autism narrative which have the ability to upset the popular neurological comprehension of the condition. They opine that a significant part of the disease framing idea of autism originates from the neurotypical community which tends to undermine the subversive and alternative potential immanent in these narratives and proposes that these counter-narratives within the neuro-diverse world could endeavour at opposing the ideological hegemonies inherent in the approaches of the neurotypicals (2008: 460-461).

Joyce Davidson and Victoria L. Henderson in "Coming out' on the spectrum: autism, identity and disclosure" borrowing queer theorists' utilization of the 'coming out' trope to address the numerous manners by which the individual on the autism spectrum chose to author their life narrative and proposes four potential methods of coming out which they call 'sense-making discourse clusters or repertoires' namely 'keeping safe', 'qualified deception', 'like/as resistance' and 'education' by which they seek to build a community (2010: 155-6). Lucina Q. Uddin addresses the significance of autobiographical memory in biomedical and psychiatric discourses which has recently begun investigating the subjective dimensions of experience of the plural methods of lived realities for an individual with autism spectrum disorder in her essay "The self in autism: A emerging view from neuroimaging". Nonetheless, she recognizes the dearth of comprehension of issues relating to agency, autobiographical memory and subjective dimensions of living (2011: 202205).

Probably the most spearheading research on autism has originated from Stuart Murray in his works on autism. In his essay titled "Autism", Murray focuses on the perceivability and expanding 
number of writings on autism and the sheer absence of people who listen to it. Murray presents the reader with a cultural trajectory of the condition and the debates encompassing it, utilizing a critical disability studies worldview. He, as well, appears to point at the provisional idea of health discourses encompassing autism by not attaching primacy to the person living with the condition. In the concluding section of his essay, Murray maintains that 'causation' and 'cure' continue to be the most significant debates on autism and proceeds to suggest how media reports have played a central role in proliferating discourses on autism and contributing to certain epistemic foundations (2011: 166-168). Addressing the materiality of autism, Giovanni Stanghellini and Massimo Ballerini in "Autism: Disembodied Existence" try to offer a phenomenological comprehension of the lived experiences of autism and recommends that persons with autism could be assessed in terms of "semantic drifting", "emotional drifting", "ontological incompleteness" and "a particular ethic rejecting common sense". By endeavoring to imply that singular subjectivity at the establishment of cognitive procedures, they point on the potential divergences on how a person uses his tactile/sensory resources to understand his immediate reality (2004: 266).

In "The Autistic Mind", Susan E. Bryson contends that the autistic mind is often susceptible to 'sensory overload' which often results in a disotorted perspective or worldview of the world as there appears to be a disjuncture in the thought processes and emotions (2005: web). G. Thomas Couser had likewise used a term "authopathology" ("Recovering" 5) to allude to a method of selfinvestigated disease/illness/disorder life-writing. These life-narratives have the disruptive potential to subvert the normative discourses of pathology. Autism life narrative tend to be a mode of self-scrutinizing life-narrative which do not tally with the records of pathology and the DSM (Diagnostic and Statistical Manual of Mental Disorders).

Monica L. Orlando in her dissertation "Relational Representation: Constructing Narratives And Identities in Autobiography About Autism" sets a relational analysis of the interaction between autistic and neurotypical persons, by which she means "a set of textual practices in life writing that foreground the relationship between multiple people, voices, and discourses... the metaphor to construct relationships between disparate lives and experiences; the challenging and complication of conventional narrative structures to better reflect nonnormative experiences" (2015: 9). Such a connection appears to be helpful in outlining the sort of associations that Mukhopadhyay depicts in his autobiography. Cynthia Lewiecki-Wilson in her paper "Rethinking Rhetoric through Mental Disabilities", outlines that the onset of disability in an individual hinders their capacity to communicate. She uses the idea of 'mediated-rhetoricity' by which a disabled person regains one's subjectivity through the narrative co-constructed by "parents, advocates, and/or committed caregivers who know the disabled person well" (2003: 157-161).

Douglas Biklen, in a similar vein, uses a comparative term "labelled autistic" in his book Autism and the Myth of the Person Alone, to allude to the symptomatic and diagnostic label given to an autistic individual instead of acknowledging his independent reality; the continuous and evolving nature of the condition establishes it as a construct and thus any specific diagnostic label which focus on the fixed temporality of the condition is bound to be futile (2005: 55). Along comparable lines, Majia Homer Nadesan in Constructing Autism composes that her work does not endeavor to locate the 'truth' of autism, which to some degree attests to my contention that there can be no universal truth to autism (2005: 7).

Jim Sinclair, co-founder of Autism Network International, in an interview with Michael Ellermann, states that autism is an integral part of an individual's (who is living with the condition) personality and there is no harm in utilizing the word as a descriptor to introduce the 
individual instead of mere appendage and Monica L. Orland leaves it to the individual to use the preferred label of their decision. Sinclair inclines toward the term 'autistic person' over 'person with autism' as the latter implies that the condition and the person are/could be separated, and that autism is not an important part of one's identity and that it suggests something adverse which is reductive than being an individual (2016: 8). Douglas W. Maynard and Jason Turowetz in "Doing Diagnosis: Autism, Interaction Order, and the Use of Narrative in Clinical Talk" states how tuning in to subjective accounts of the patients have come to assume an important role in clinical practice. They opine that a lot of clinical practices have depended on interactional storytelling to draw a distinction between physician's narratives and patient's subjective accounts. By testing the profundity of the autistic person's stories, collaborate and aid their diagnosis (2017: 256-257).

Heather Thomas in "Storying Autism" alludes to three monographs-Jordynn Jack's Autism and Gender, AnneMc Guire's War on Autism, and Melanie Yergeau's Authoring Autism and seeks to posit that these narratives tend to bring autism narratives to the foreground in the social order which often sidelines autism narratives. Thomas further contends that autism narratives likewise endeavor to undo the violence (social, rhetoric and otherwise) meted out to them (2018: 2-3). In "Embodied Consciousness: Autism, Life Writing and the Limits of the Cognitive Paradigm", Ajitpaul Mangat goes to the extent of saying that autism life-narratives reconsider and revise consciousness for consciousness is profoundly dependent on language. Having said that, the body comes to assume an important role in meaning making processes (2017: 72).

\section{CONCEPTUAL FRAMEWORK/METHODOLOGY}

This current research study is qualitative in nature which is fundamentally a close reading of Tito Mukhopadhyay's autobiography dependent on the extant literature in the fields of cognitive neurosciences, autobiographical studies, critical disability studies and the health humanities, to list a couple. What this paper endeavors to do is attempt at creating a dialogue/exchange between research of life writing studies on health anomalies and the health humanities by trying to foreground the provisionality of identities of the person on the autism spectrum.

Using critical methodologies from narrative theory, poststructuralism, phenomenology and critical disability studies, the paper tries to investigate the subjectivity of the individual who narrativizes the materiality of autism, and the ways in which he exercises narrative agency the autiobiographical account which highlights the postmodern predilection of the fluid nature of identities and selves. To arrive at this fact, the researcher has utilized secondary sources such as books, journals, articles, dissertations and the like to bring out the polyvalent and ambivalent nature of identity formation in autism.

\section{ANALYSIS}

In the Foreword to Tito Mukhopadhayay's life account, Lora Wing states that, before Tito's arrival at the Center for Social and Communication Disorders, Tito had displayed practices that was past the lectern of commonsensical understandings of mental/cognitive disabilities. It was accepted that people with autism have at least one or more talents that are far ahead of their capacities, for example, abilities including visuo-spatial or repetition memory aptitudes, for example, schedule estimations, numbers, drawing recollecting train time tables, etc. In any case, Tito was evidently ready to utilize long words in complex sentences and to communicate philosophical musings about existence (1). Tito's wonderful capacity lay in his ability to convey messages utilizing an 
alphabet board from the age of six. With the guide of his mother, he recorded the letters in order on a bit of paper. He had the option to react to the inquiries by highlighting the letters on the letter set board to spell his answers. From right off the bat in his life, Mukhopadhyay gave away from of good intellectual capacity through his acknowledgment of and the capacity to coordinate numbers, letters and shapes. His exceptional capacities focus to a specific "narrative appeal" that Stuart Murray alluded to in his exposition on autism account. The narrative appeal of an "autiebiography" is the capacity of a book to "show a specific type of individual otherness" (28). Without a doubt, it is the personification of alterity and otherness: an individual, much the same as you or me who is in reality in no way like you or me, yet somewhat subject to a condition that as far as anyone knows defies rationale and comprehension (38). In the initial segment of his autobiographical narrative titled "The Voice of Silence", Tito expresses that, individuals would regularly be humiliated or stressed by his activities and specialists would utilize various wordings to portray his condition, unfortunately. In the entire corpora of his autobiographical narratives, Tito depicts his relationship with his mom by acquiring a similarity of the hand and its shadow. It was his mom's lap, which had the warmth and readiness which caused him to associate, notwithstanding his numerous endeavors of pulling back into himself. He depicts cases when he was troubled with a constant feeling of feeling of disgrace.

Mukhopadhyay endeavors to re-develop a 'self after the interruption of the rationality of oneself, post analysis which is at difference with essentialized biomedical fixities. In a large number of Tito Mukhopadhyay's autobiographical accounts, the reader is made mindful of the way that, autism influences his perspective on the world as well as his wonderful motivations. Tito's tactile recognition is obviously altered by his condition. Since he cannot associate synchronous sense encounters, he frequently centers around his sound-related sense, which he considers more impressive than his vision (112). In addition, Tito has partial synesthesia (184) which is the reason he regularly sees sounds or feelings as colours (157). Tito's divided tactile experience (212) hinders him from framing a sound comprehension of the world. Tito much of the time encounters an impression of losing his body. In some cases, he portrays himself as a bodiless disembodied being; at different occasions, his body is by all accounts dispersed and incontrollable. In his autobiographical narrative, Tito for the most part, discusses himself as an outsider looking in, he reports that " $[t]$ he kid would not acknowledge the presence of his body, and envisioned himself to be a soul" (19). Because of his virtual being, he was losing authority over his body. A feeling of denial was firm to such an extent that he was unable to react to any circumstance the manner in which it ought to have been done (22). In his life narrative, every section tends to a part of his psychological experience, starting with his youth in Mysore and Bangalore, and traveling through youthfulness in Los Angeles and Austin, Texas. The brain/body dichotomy is the focal string to his accounts. Through Tito's self-portraying narrative, we are additionally given bits of his family and his relationship with his grandparents, and this acquires urgency to seeing how, on occasion, they helped him to conquer the disgrace, stigma and disgrace that encompassed his condition. He likewise refers to how recollections of having lived with them helped Tito to build an account from the shards of his fragmentary memory. Tito portrays how his family looked downward on his mom for her withstanding enthusiasm for scrutiny. As he states, she was awful, as the family members felt that married women who were mothers ought not to study, disregarding their children. In a nation where demise is venerated, where penance is revered, where aspiration is viewed as the way to insatiability and bad habit, she was awful. He likewise depicts his clever relationship with the flight of stairs, which at an early age, he accepted that, it would prompt God. Tito relates an occurrence at the specialists loads where he had pushed and pulled his folks towards the flight of stairs, a lot to the marvel of the individuals around, driving the specialists to 
infer that Tito had cerebral paralysis. At that point, he proceeds to portray his intermittent dream in which he is joined by a noble man, who tailed him all over the place. After a point, he lost contact with every one of these pictures that conformed to him. In the early long stretches of his life, after finding Tito's condition, individuals had proposed that the child be taken to a close by sanctuary which had a recuperating emanation around it. Since, just a supernatural occurrence could fix him.

In his paper "Autism and Culture," Joseph Strauss proposes a biocultural model of autism in which he recommends that, as a personality gathering, autism is to some degree nebulous, comprehensive, and heterogenous. In current reasoning, autism lies along a range, a slick straight movement from "low functioning" to "advanced." Given the expanding size and assorted variety of the populace labelled as autistic, be that as it may, it may be smarter to consider it an agglomeration, a system of covering subgroups, and with the gathering overall characterized by limits that are remarkably penetrable and permeable. Inside people, indications of this condition may fundamentally shift. Mukhopadhyay, at one point in his narrative expresses: "Rather than considering autism a sickness, with understandable reason, a determinate finding, and a potential fix, it may be progressively gainful to consider it an infection element, which, permits us to move away from the positivist sort of illustrative classes of ailment and to consider ailments not as discrete items yet as scopes of substantial contrasts and response (22)

This is the thing that Strauss implied by a "biocultural model of autism", one that examines illness and disease as rising up out of an unpredictable connection of science and culture. Eric L. Santner investigates the possibility of narrative fetishism in his article "History Beyond the Pleasure Principle" where he characterizes it as, the development and arrangement of an account intentionally or unknowingly intended to erase the hints of the injury or misfortune that called the account into being in the first place (14). So accounts, when fetishized, can turn into a method of closing our ears to what damages and alarms us the most, a method of not just narrativizing our hushes, yet additionally freeing oneself of the disgrace coming about because of the social exclusion and denunciation. A significant part of the verbal portrayal or motioned portrayal was the side-effect of a great part of the social attacks. In his account, Tito, at specific cases, pulled back into his mom's lap as a result of the social segregation. In his account, Tito depicts his experience of figuring out how to ride a cycle and his quality in a party would prompt laughs.

Tito's anomalous embodiment empowered him to recall things and occasions by affiliations. After the passing of Tito's grandfather, he would persuasively ascend to the bed where the cadaver of the deceased was kept. After observing that, the incense sticks were being lit around the bed, the kid thought they were loving the body, and it drove him to draw the relationship of the flight of stairs that he accepted, prompted God. He reasoned that, what amazing things death could do to an individual. What's more, at that point he chose to work for it. After the demise of his grandfather, Tito believed himself to be a soul without the presence of a body. Such instances are significant in underscoring how individuals on the autism spectrum exercise narrative agency which enable them to envision alternative possibilities of writing one's life. Here, with the guide of the white board and his mom, Tito had the option to narrativize his own encounters.

The storyteller narrativizes that, Tito's mother finds intriguing awards for her child's undertakings. For example, she shoots an image of him toward the finish of every day. The possibility of seeing himself in a photo is profoundly persuading for Tito, in all probability since it furnishes him with a picture of his entire and un-dissipated body (151). Physical as well as subjective enhancements are outwardly (re)constructed. Tito is very much aware that his mind is plastic and versatile as long as he puts forth an attempt to change its circuits: With each new 
expertise I learn, more regions of my mind are worked out. [...] Mother would get back home and attract outlines to give me what my nerves were doing when I battled with bringing down directed words. On the initial hardly any days, she would draw the dendrites and make a chain of them. She would attract them gently to show a weak association among them. As days passed, she would show a darker association between them since they should pick up in quality as I rehearsed. I could envision the neurons making a pathway in my mind, as I indicated more inspiration and less opposition. (171) Here, Tito alludes to the moderately late logical revelation that the mind is moldable and versatile in outset as well as in adulthood too. New discoveries in the field of neuroplasticity, the capacity of the mind to re-envision itself because of experience, have prompted critical advancements in the treatment of autism. The story refers to a fanciful discussion between the autistic child and the youngster specialist, in which, after the therapist analyze the group of having "autism", the child supposedly further pulls back into himself. As the narrator lets us know, the child was losing authority over his body. The feeling of disavowal was strong to the point that he was unable to react to the circumstance the manner in which it ought to have done. The narrator likewise portrays the autistic child's commitment with various exercises that includes the utilization of one's psychological capacities like illuminating jigsaw riddles and crosswords. As the kid felt his intellectual capacities were comparable to every other person, he felt that his body was dispersed and it was hard to gather it together. Such accounts can empower the profitable cooperation of the voices of the writers and critics in manners that can endeavor to engage instead of adventure the debilitated subject. At one example, in his collection of memoirs, Tito describes: Since I realized I was mentally unbalanced, I started to bunch things under it. I made up an entire rundown of things that I thought had mental imbalance. The drapes that moved in the breeze, the of all shapes and sizes leaves that moved somewhat more with the air in view of their suspended positions, the small amounts of paper, or the pages of an open book under a fan were delegated autistic. They were influenced with autism since they fluttered, in light of the fact that they would not react to any squares, since they didn't talk, and I was certain that they would not have the option to impersonate the clinical analyst. (28) Through the course of Tito's clever disruption, autism turns out to be less a signifier of pathology than a term for his feeling of outrageous association or animistic compassion, a term that re-arranges the world, destroying the benefit that takes care of the neurotypicals.

\section{[Not] a Conclusion}

The above analysis of Tito Mukhopadhyay's autobiographical narrative leaves open several other possibilities of exploring the lived realities of autism. The modes of assuaging distress and expunging trauma through narrative possibilities envisioned by Mukhopadhyay need not be the potential barometer for analyzing similar accounts of living with autism. Such accounts can empower us to reconsider the role of the autistic individual to be the potential architect of his own autobiography by not necessarily being the sovereign, autonomous self of autobiographical accounts. Several instances that have been fleshed out from the narrative, likewise enables one to rethink the concept of neurodiversity which does not bring in the various shades of human difference into their accounts. The neurological makeup of persons cannot be discerned on the basis of an archived set of symptoms and case studies. What clinicians, psychologists, psychoanalysts need to consider are the various subjective dimensions of experience. Though there have been positive outcomes with the intervention of the narrative turn in psychology and medical sciences, there is still a long and onerous path to tread. Mukhopadhyay exercises narrative agency in that it basically attempts to de-pathologize the affliction and recover one's 
lost agency in life narratives, thereby illustrating that autism is not a marker of deficit, lack and an aberrant pathology, bizarre and convoluted linkages, but how the brain constitutes the narrative in different capacities. Jason Tougaw in "Beyond Brainhood: The Autism Memoirs of Naoki Higashida and Tito Mukhopadhyay" had stressed on how the brain of the autistic individual comes to play a seminal role in their mode of being in the world and experiencing the world. Borrowing Joseph Strauss' idea of "network of associations" Tougaw stressed on how Mukhopadhyay narrative invites the readers into his private world of meaning making and becoming self (5). I concur with Tougaw's contention that the brain comes to perform an important role in one's mode of becoming and a state of tussling between selves and their brains, or the sufferings and their selves, as Tougaw had noted. For, Mukhopadhyay's autobiographical narrative emerges out of a cultural imaginary which is the sum total of physiology, psychology, social expectations, family and various other parameters. However, to reiterate, Tito Mukhopadhyay's narration in his autobiography does not, in any way, foreclose other possibilities of envisioning one's identity and subjectivity of living with autism.

Through Tito's narrativization of his encounters, Mukhopadhyay has attempted to erase the hints of injury, disgrace and hushed attitudes that encompass his condition, while likewise exhibit the limit of life stories to encourage the social connection between scholars in the exchange of understandings of disability. However, the autobiographical narrative starts by concentrating on the impediments of existence with autism, it journeys toward better approaches for getting to accept one's disability and regain agency over one's life. Through these stories, individuals living with such an incapacitating condition, are revealed as individual people, with a diverse method of understanding the world. Writers like Mukhopadhyay stress on the need to exorcize a portion of the fantasies related to such a health condition, and as Mukhopadhyay's narrative appears to show, autie-life story/histories can without a doubt, be a legitimate confirmation of an individual living with cognitive incapacity, and can indeed enrich the diagnosis procedures of medical practitioners and psychologists. Disability life-narratives, through their depiction of the materiality of autism, might have the option to move the reader, advance self-reflection, and challenge predetermined assumptions on handicap. Additionally, they may convey the possibility that pity is not a sufficient enthusiastic reaction to handicap or debility, driving the reader to perceive individuals with inabilities as an unmistakable social gathering that demand explicit social rights. All things considered, these accounts lead the reader to rethink an alternative method of seeing the debilitated individual, the wide corpus of neurodiversity and furthermore, the genre of life narratives. Along these lines, while we are distinctly mindful that these narrative demonstrations and readings are not the slightest bit an adequate ground for social change, they can be seen in any event as a vital ground (Schaffer and Smith 226).

\section{LIMITATIONS OF THE STUDY}

The purpose of the current research was to investigate the nuances of narrativizing shame, distress and stigma and narrative agency in Tito Mukhopadhyay's autobiographical narrative relying on the primary text and several other secondary sources. The obvious lacuna of the essay was in its inability to explore other genres (biography, memoir, fiction, poetry, essays and testimonies) and what rhetorical strategies, silences and tropes they employ in describing the lived realities of autism. This unexplored territory could be taken up as a possible future research venture. 


\section{REFERENCES}

Bieniarz, Anna. (2011). "Loneliness and Silence in Autism- Implications for Psychotherapy". Autism - A Neurodevelopmental Journey from Genes to Behaviour. Ed. Valsamma Eapen. https://www.intechopen.com/books/autism-a-neurodevelopmental-journey-from-genes- tobehaviour/loneliness-and-silence-in-autism-implications-for-psychotherapy. Retrieved June 20, 2020. DOI: $10.5772 / 17931$

Biklen, Douglas et.al. (2005). Autism and the Myth of the Person Alone (Qualitative Studies in Psychology Book 3). New York: NYU Press.

Broderick, Alicia A. \& Ari Ne'eman. (2008). “Autism as metaphor: narrative and counter-narrative.” International Journal of Inclusive Education. Vol 12, Issue 5-6: Disability Studies in Education. https://doi.org/10.108o/13603110802377490

Bryson, Susan E. (2005). “The Autistic Mind” The Neurobiology of Autism. Eds. Margaret L. Bauman and Thomas L. Kemper. Baltimore: Johns Hopkins University Press.

Couser, G. Thomas. (2017). Body Language: Narrating Illness and disability. (Life Writing). New York: Routledge.

Couser, G. Thomas. (1997). Recovering Bodies: Illness, Disability and Life Writing (Winconsin Studies in Autobiography). Madison: University of Winconsin Press.

Davidson, Joyce \& Victoria L. Henderson. (2010). 'Coming out' on the spectrum: autism, identity and disclosure”. Social E Cultural Geography. Vol 11, Issue 2, pp. 155-170.

https://doi.org/10.108o/14649360903525240

Ellermann, Michael. (2016). "Interview with Jim Sinclair" (PDF). Michael Ellerman

https://www.autism.se/RFA/uploads/nedladningsbara\%2ofiler/Interview_with_Jim_Sinclair.pdf Retrieved June 21, 2020.

Frith, Uta \& Francesca Happe. (2002). "Theory of Mind and Self Consciousness: What is it like to be Autistic?” Mind E Language, Volume 14, Issue 1. https://doi.org/10.1111/1468-0017.0010o

Frith, Uta. (2008). “The changing face of autism” Autism: A Very Short Introduction. London: OUP.

Goidsenhoven, Leni Van. (2017). “Autie-Biographies: Life Writing Genres and Strategies from an Autistic Perspective”. Journal of Language, Literature and Culture, Vol 64, Issue 2, pp. 79-95. https://doi.org/10.1080/20512856.2017.1348054

Hacking, Ian. (2009). “Autistic Autobiography”. Philos Trans R Soc Lond B Biol Sci. 364 (1522): pp. 1467-73. Hillary, Alyssa. (2020). "Autist/Biography” The Palgrave Handbook of Auto/Biography. Eds. Julie M. Parsons and Anne Chappell. London: Palgrave Macmillan.

Kellman, Julie. (1999). "Drawing with Peter: Autobiography, Narrative, and the Art of a Child with Autism”. Studies in Art Education: A Journal of Issues and Research. Vol. 40, Issue 3, pp. 258-274. DOI: 10.1080/00393541.1999.11650061

Lourens, Heidi. (2016). "Driving in unheard silence: Disability and the politics of shutting up". Journal of Health Psychology. SAGE Journals. https://journals.sagepub.com/doi/abs/10.1177/1359105316643856. Retrieved June 22, 2020. https://doi.org/10.1177/1359105316643856

Mangat, Ajitpaul. (2017). "Embodied Consciousness: Autism, Life Writing and the Limits of the Cognitive Paradigm”. Explorations of Consciousness in Contemporary Fiction 51 (Consciousness, Literature and the Arts) Eds. Grzegorz Maziarczyk \& Joanna Klara Teske. Netherlands: Brill Rodopi.

Maynard, Douglas W. \& Jason Turowetz. (2017). "Doing Diagnosis: Autism, Interaction Order, and the Use of Narrative in Clinical Talk." Social Psychological Quarterly. https://doi.org/10.1177/0190272517720683 
Mukhopadhyay, Tito. (200o). Beyond the silence: My Life, the world and autism. UK: National Autistic Society.

Murray, Stuart. (2011). Autism (The Routledge Series Integrating Science and Culture). New York: Routledge.

Murray, Stuart. (2008). Representing Autism: Culture, Narrative, Fascination (Representations: Health, Disability, Culture and Society). Liverpool: Liverpool University Press.

Nadesan, Majia Homer. (2005). Constructing Autism. New York: Routledge.

Orlando, Monica L. (2015)."Relational Representation: Constructing Narratives and Identities in Autobiographies about Autism"

https://etd.ohiolink.edu/!etd.send_file?accession=case1427986813\&disposition=inline. Retrieved June 20, 2020.

Osteen, Mark. (2010). Autism and Representation. New York: Routledge.

Rose, Irene. (2008). "Autistic autobiography or autistic life narrative?" Journal of Literary \& Cultural Disability Studies. Vol.2: Issue 1, pp. 44-54. https://doi.org/10.3828/jlcds.2.1.6।

Santner, Eric L. (1992). "History beyond the Pleasure Principle: Some Thoughts on the Representation of Trauma." Probing the Limits of Representation: Nazism and the "final Solution, vol. 144. pp.102-103.

Savarese, Ralph James. (2013). "Toward a Postcolonial Neurology: Autism, Tito Mukhopadhyay and a new Geo-Poetics of the Body" Foundations of Disability Studies. Eds. Matthew Wappett \& Katrina Arndt. New York: Palgrave Macmillan.

Schaffer, Kay, and Sidonie Smith. (2004). Human Rights and Narrated Lives: The Ethics of Recognition. New York: Palgrave Macmillan.

Stanghellini, Giovanni \& Massimo Ballerini. (2004). "Autism: Disembodied Existence”. Philosophy, Psychiatry \& Psychology, Volume 11, Number 3, pp. 259-268. https://doi.org/10.1353/ppp.2004.0069

Strauss, Joseph. (2013). “Autism and Culture.” The Disability Studies Reader, ed. Lennard J. Davis. New York: Routledge.

Thomas, Heather. (2018). "Storying Autism". Composition Forum 39.

https://files.eric.ed.gov/fulltext/EJ1188976.pdf. Web. Retrieved June 22, 2020.

Tougaw, Jason. (2015). "Beyond Brainhood: The Autism Memoirs of Naoki Higashida and Tito Mukhopadhyay". Web. Retrieved June 20, 2020.

Uddin, Lucina Q. (2011). “The self in autism: An emerging view from neuroimaging” Neurocase, Jun; 17(3): 201-208. doi: 10.1080/13554794.2010.509320.

Wexler, Alice. (2016). Autism in a Decentered World (Routledge Advances in Disability Studies). New York: Routledge.

Wilson, Cynthia Lewiecki. (2003). "Rethinking Rhetoric through Mental Disabilities" Rhetoric Review. Vol. 22, No. 2 156-167. Retrieved June 22, 2020, from www.jstor.org/stable/3093036 